\title{
Seismic Resistant Design Method for Open-Type Wharf with Pneumatic Caisson Foundation
}

\author{
Daisuke Shibata $^{1 *}$, Takashi Nagao ${ }^{2}$ \\ ${ }^{1}$ Japan Port Consultants, Ltd., TK Gotanda Bldg., 8-3-6, Nishi-Gotanda, Shinagawa-ku, Tokyo, Japan \\ ${ }^{2}$ Research Center for Urban Safety and Security, Kobe University, 1-1, Rokkodaicho, Kobe-shi Nada-ku, Hyougo, Japan
}

Corresponding Author Email: daisuke_shibata@jportc.co.jp

https://doi.org/10.18280/ijsse.100207

Received: 28 January 2020

Accepted: 2 March 2020

\author{
Keywords: \\ seismic resistant design, open-type wharf, \\ acceleration response, damping constant
}

\begin{abstract}
An open-type wharf with a pneumatic caisson foundation has strong earthquake resistance because of its high foundation rigidity, but the existing practical earthquake resistant design methods for an open-type wharf have been established only for a wharf with a steel pipe pile foundation. To follow this design procedure may be appropriate, however, the difference in the rigidity of foundation between the two structural types should be considered. The authors conducted two-dimensional finite element earthquake response analyses, modelling both open-type wharves with pneumatic caissons and soil layers, and discussed their earthquake responses. The earthquake response of the wharf with pneumatic caissons was shown to be different from that on a steel pipe pile foundation. Design procedure for an open-type wharf with pneumatic caisson foundation was proposed.
\end{abstract}

\section{INTRODUCTION}

The construction method of a pneumatic caisson foundation consists in the following: fabricating in advance at ground level reinforced concrete caissons with a working chamber in the lower part; removing underground water by pumping into the working chamber compressed air that countervails the pressure of water; carrying out extraction and immersion of caissons under a constantly dry condition; and installing the structure at a prescribed position.

A pneumatic caisson foundation is a structure having an excellent load bearing performance against horizontal and vertical loads, which derives from embedding highly rigid caisson bodies into the ground and making the caissons tightly constrained by the ground under the bottoms and by the side faces of the caissons. Thus, this foundation offers a tenacious structural resistance against sliding or overturning that can be caused by a seismic force. Consequently, this construction method is applied to a variety of underground structures, such as foundations of bridges, foundations of road and railway viaducts, foundations of buildings, and vertical shafts in shield tunnels, but there are few applications to port and harbor related structures. This is presumed to be largely because the design method for a pneumatic caisson foundation, assumed to be applied to the port and harbor sector, is yet to be established.

In recent years, wharves with larger depth have been required in Japan to respond to larger sized container ships and increased port calls of cruising vessels. In addition, construction of earthquake resistant port structures has also become important in association with the concern over the possible outbreak of a large-scale earthquake. This leads one to think that in the port and harbor sector, demand for opentype wharves with a pneumatic caisson foundation will increase because of the potential applicability to wharves requiring stronger earthquake resistivity or greater berth water depth. Establishment of the design method is therefore urged.

In Japan, design of a wharf is carried out in accordance with the "Technical Standards and Commentaries for Port and Harbour Facilities (hereafter referred to as the "Port Standards.") [1]. The type of wharf assumed in the Port Standards is the one having a steel pipe pile foundation only, which means that there is no stipulation for a design method that assumes a wharf with a pneumatic caisson foundation. For this reason, to follow in principle the method provided for in the Port Standards seems to be appropriate when establishing a design method for a wharf on the pneumatic caisson foundation. There is, however, a big difference in the rigidity of foundation between the steel pipe pile foundation and the pneumatic caisson foundation, hence a difference in behavior is assumed under an earthquake between a wharf having a steel pipe pile foundation and one having a pneumatic caisson foundation. For establishing a design method for a wharf with a pneumatic caisson foundation, clarification of the seismic difference in behavior needs to be carried out first, and then proceed to build a method that reflects the seismic behavior of the wharf with a pneumatic caisson foundation. This study will discuss the seismic behavior of a wharf with a pneumatic caisson foundation using a two-dimensional non-linear finite element analysis. Focusing on the time around which maximum response acceleration occurs at the crown of a wharf, we arranged the response displacement distributions of a pile, which resulted in an almost linear trend, and we reported [2] that in the case of a highly rigid pneumatic caisson foundation, vibrations centering around the virtual fixed point as in the case of a steel pipe foundation are not generated, but they are centering around the bottom end of a pile as is the behavior of a rigid body. This study has arranged horizontal acceleration time histories evaluated at the central part of the crown of the wharf, at the sea-side pile position, and at the land-side pile position; and examined appropriate damping constants for use for calculating acceleration response spectra by focusing on 
the phase difference of horizontal acceleration time histories at the respective pile positions.

\section{EARTHQUAKE-RESISTANT DESIGN METHOD FOR WHARF ON STEEL PIPE PILE FOUNDATION}

The Kobe earthquake in 1995 triggered the adoption in Japan of the following two-stage earthquake ground motions as the design input motions in designing earthquake-resistant infrastructure facilities: Level 1 earthquake ground motions (motions which presumably occur with such degree of frequency as can be experienced during the period of conducting design work) and Level 2 earthquake ground motions (motions which have the intensity of the maximum scale potentially occurring at the referenced places from the present to the future). Accordingly, the Port Standards have introduced the two-stage design method, as well. The design input earthquake ground motions specified in the Port Standards are characterized by the requirement of establishing site dependent motions. Designers engaged in the design work are required to establish earthquake ground motions that reflect the amplifying characteristics of the motions occurring from the seismic bedrock to the engineering bedrock on each of the sites for designing port structures. Consequently, different design input earthquake ground motions are established for the respective ports using a time history waveform format.

This study focuses on Level 1 earthquake ground motions out of the two-stage ground motions, and the forthcoming sections will limit descriptions to earthquake resistant design method corresponding to Level 1 earthquake ground motions. Verification of seismic performance against Level 1 earthquake ground motions shall basically apply a simplified method that uses a seismic intensity method for evaluating the seismic influence by replacing the influence of the dynamic forces due to the earthquake ground motions with static inertial force. Here, the seismic coefficient to be established for verifying earthquake resisting performance of a port structure, when applying the seismic intensity method for a Level 1 earthquake, shall be called "a seismic coefficient for verification".

The concept of the seismic coefficient was proposed by Sano in 1916 [3], with the basic concept as follows: when acceleration $\alpha$ acts on a body with mass $m$, inertial force $m o$ will work in the opposite direction of the acceleration. Here, inertial force shall be expressed as $F$ and the weight of the body as $W$, then the following equation shall apply:

$$
F=\frac{\alpha}{g} W
$$

Furthermore, if $\alpha / g$ is expressed instead as $k$, the equation becomes:

$$
F=k W
$$

This $k$ is called a design seismic coefficient. Multiplication of the weight of the structure by the seismic coefficient will yield inertial force generated by earthquake ground motions.

The wharf is, as shown in Figure 1, a rigid-frame structure being configured by a steel pipe pile foundation and a superstructure made of steel reinforced concrete. In the earthquake-resistant design of a wharf, rigid-frame structures are analysed using a frame model, and safety margins of the structural components are figured out by statically applying the inertial force of the superstructure calculated from the design seismic coefficients. The seismic coefficient is calculated by the following process:

(i) Using a one-dimensional earthquake response analysis that models the subsoil of the central part of the wharf structure, the response acceleration time history at the position $1 / \beta$ below the virtual ground surface is obtained. The virtual ground surface is meant to be a gradient face equivalent to a half elevation between the frontal water depth and the actual slope. In addition, $\beta$ is a parameter called a characteristic value of a pile that appears in a deflection curve of a beam on the elastic foundation and is obtained from

$$
\beta=\sqrt[4]{\frac{k_{C H} D}{4 E I}}
$$

where,

$\beta$ : Characteristic value of the pile $\left(\mathrm{cm}^{-1}\right)$,

$k_{C H}$ : Coefficient of subgrade horizontal reaction $\left(\mathrm{N} / \mathrm{cm}^{3}\right)$,

$D$ : Pile width $(\mathrm{cm})$

$E I$ : Bending rigidity of pile $\left(\mathrm{N} \cdot \mathrm{cm}^{2}\right)$.

Here, the reason for setting the position where the response acceleration time history is evaluated at $1 / \beta$ below the virtual ground surface is in order to regard $1 / \beta$ as the fixed point of the pile according to the deflection theory of the beam on elastic foundation, and to take into consideration the pileground interaction in the range from the seabed to the fixed point.

(ii) Acceleration response spectra with a damping constant of $20 \%$ are obtained from the response acceleration time history at $1 / \beta$ below the virtual ground surface computed by the one-dimensional earthquake response analysis. The reason for setting this value as the damping constant is that evaluation of acceleration response spectra by the one-dimensional earthquake response analysis of horizontal stratification does not permit consideration of the influence of the actual slope or the damping effects due to the existence of piles in the central part of the actual wharf, and this makes it appropriate to set an apparent damping constant larger than that of the structural body when finding the earthquake response at the crown of the wharf

(iii) Apart from the above, if the frame analysis enables the relation between the load and the displacement when a minor load is acted on a wharf to be found, it will allow establishment of spring constants as a wharf, and Equation (4) will yield a natural period.

$$
T_{s}=2 \pi \sqrt{\frac{W}{g K}}
$$

where,

$T_{s}$ : Natural period of the wharf (s)

$W$ : Empty weight on one pile line and surcharge at earthquake $(\mathrm{kN})$

$g$ : gravity acceleration $\left(\mathrm{m} / \mathrm{s}^{2}\right)$

$K$ : Spring constant of the wharf $(\mathrm{kN} / \mathrm{m})$

Maximum response acceleration corresponding to the natural period of the wharf is found on the basis of the aforementioned acceleration response spectra, and the seismic 
coefficient for verification is obtained as a result of dividing the maximum response acceleration by gravity acceleration.

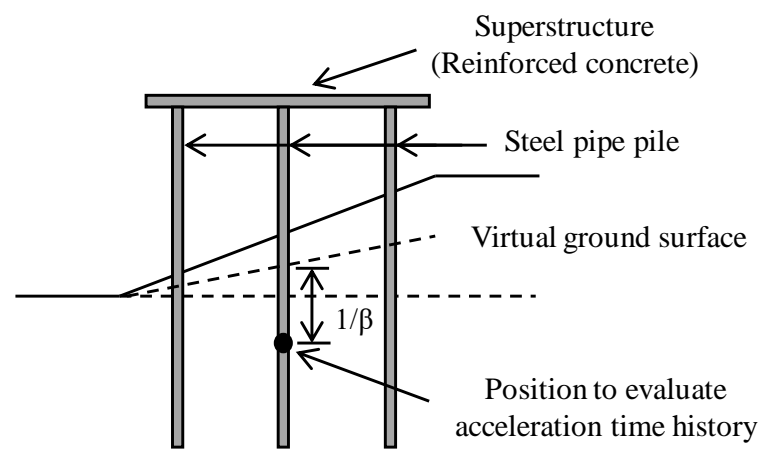

Figure 1. Sketch of open-type wharf on vertical piles

\section{EARTHQUAKE RESPONSE OF WHARVES WITH CAISSON FOUNDATIONS}

\subsection{Method of analysis}

Three cases of wharves with pneumatic caisson foundations were studied in this research. Figures 2 to 4 illustrate wharf structures and their numerical modelling. The lateral area of the model is set to $100 \mathrm{~m}$ away from the centre of the wharf so as to avoid the effect of reflection wave from the lateral boundary on the wharf. Liquefaction effect is considered for the reclaimed soil layer of Case A only, with the remaining layers being assumed as free from liquefaction. Table 1 shows dimensions such as caisson foundation pitch and caisson foundation diameter of the respective wharves.

The evaluation method for earthquake response of a wharf with a pneumatic caisson foundation is the two-dimensional nonlinear finite element analysis. The method has been used for the reproduction of damage of a wharf by earthquake [4] and experimental result from testing a wharf [5]. Also, some studies have been done for the earthquake response evaluation of open-type wharves by use of the method [6-8]. However, few studies have been done for the earthquake response evaluation of open-type wharf with pneumatic caisson foundation $[9,10]$. The advantage of the two-dimensional nonlinear finite element analysis is that it allows evaluation of the time history nonlinear behaviour of soil and structure and the effect of liquefaction for those soil layers potentially exposed to liquefaction. In addition, the numerical method models wharves and surrounding subsoil, thereby enabling the evaluation of structure-soil dynamic interaction. In this research, the analytical code FLIP [11] was utilized for the two-dimensional nonlinear finite element analysis. FLIP adopts a multi-spring model [12] as the model to stipulate dynamic deformation characteristics of soil. The nonlinear characteristic of the soil is expressed by a hyperbolic model as in Eq. (5) [13].

$$
\tau=\frac{G_{0} \gamma}{1+\left|\frac{\gamma}{\gamma_{r}}\right|}
$$

The elastic shear modulus of soil in general depends on mean effective confining pressure. With the increase of depth, the mean effective confining pressure will increase and the elastic shear modulus will rise as well. The confining pressure dependency is considered to be proportional to the 0.5 th power of the mean effective confining pressure [14] as shown in Eq. (6).

$$
G_{0}=G_{m a}\left(\frac{\sigma_{m}^{\prime}}{\sigma_{m a}^{\prime}}\right)^{m_{G}}
$$

where, $G_{0}$ is the initial shear modulus $\left(\mathrm{kN} / \mathrm{m}^{2}\right), \gamma$ is the shear strain, $\gamma_{r}$ is the reference shear strain $\left(=\tau_{f} / G_{0}\right), \tau_{f}$ is the shear strength $\left(\mathrm{kN} / \mathrm{m}^{2}\right), G_{m a}$ is the initial shear modulus under reference effective confining pressure $\left(\mathrm{kN} / \mathrm{m}^{2}\right), \sigma_{m a}{ }^{\prime}$ is the reference effective confining pressure $\left(\mathrm{kN} / \mathrm{m}^{2}\right), \sigma_{m}{ }^{\prime}$ is the effective confining pressure $\left(\mathrm{kN} / \mathrm{m}^{2}\right)$ and $m_{G}$ is the parameter indicating dependency on confining pressure $(=0.5)$.

Soil parameters were set according to Morita et al. [15].

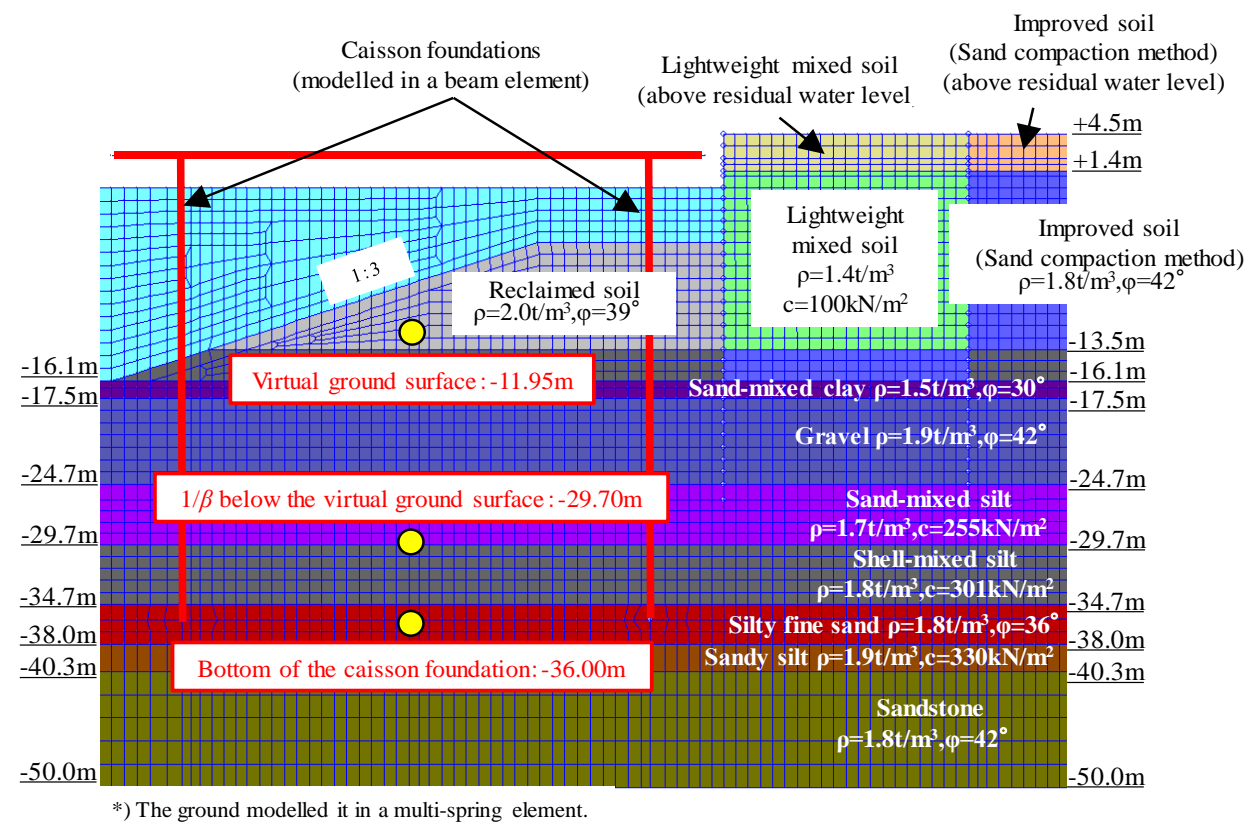

Figure 2. Numerical model (Case A) 


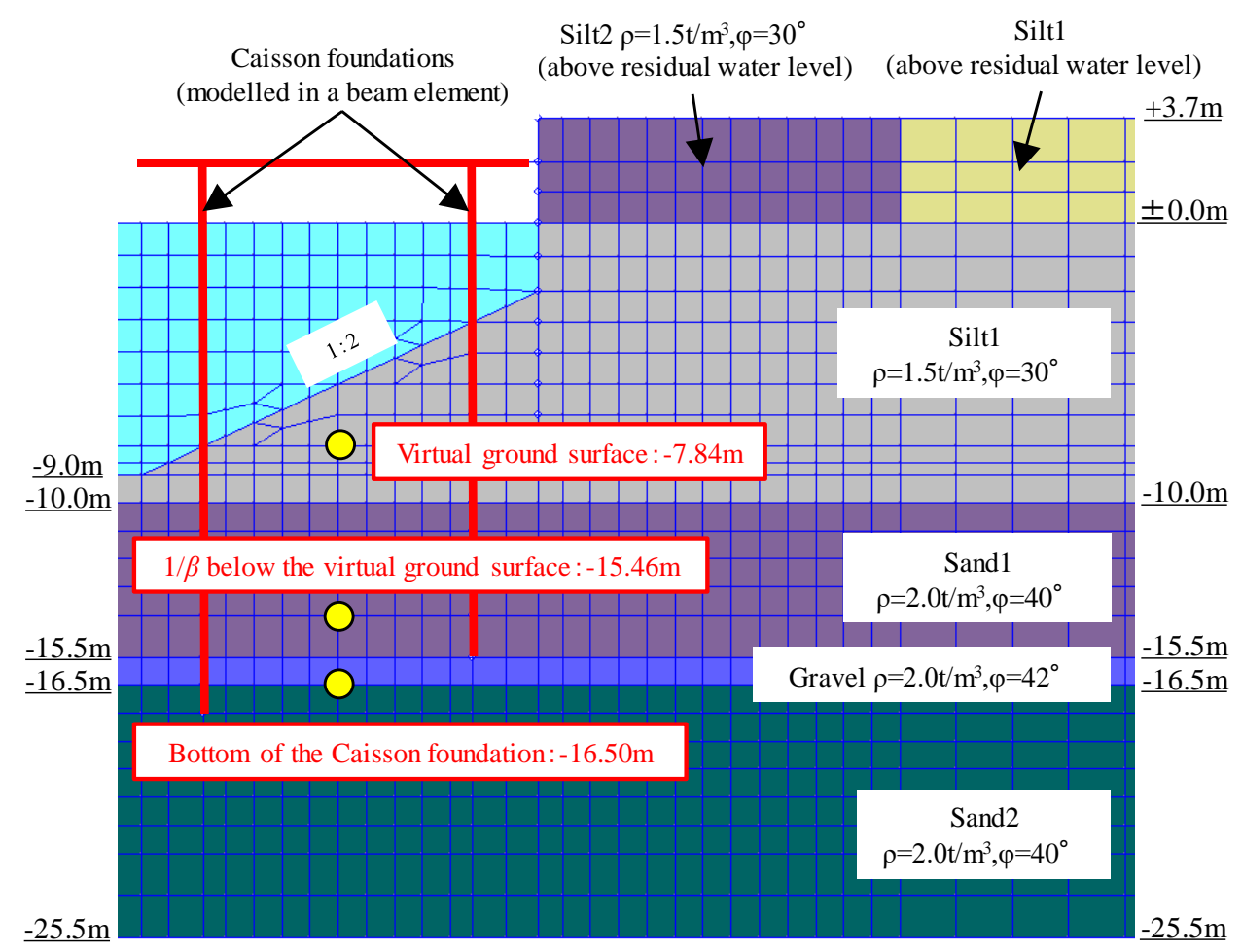

*) The ground modelled it in a multi-spring element.

Figure 3. Numerical model (Case B)

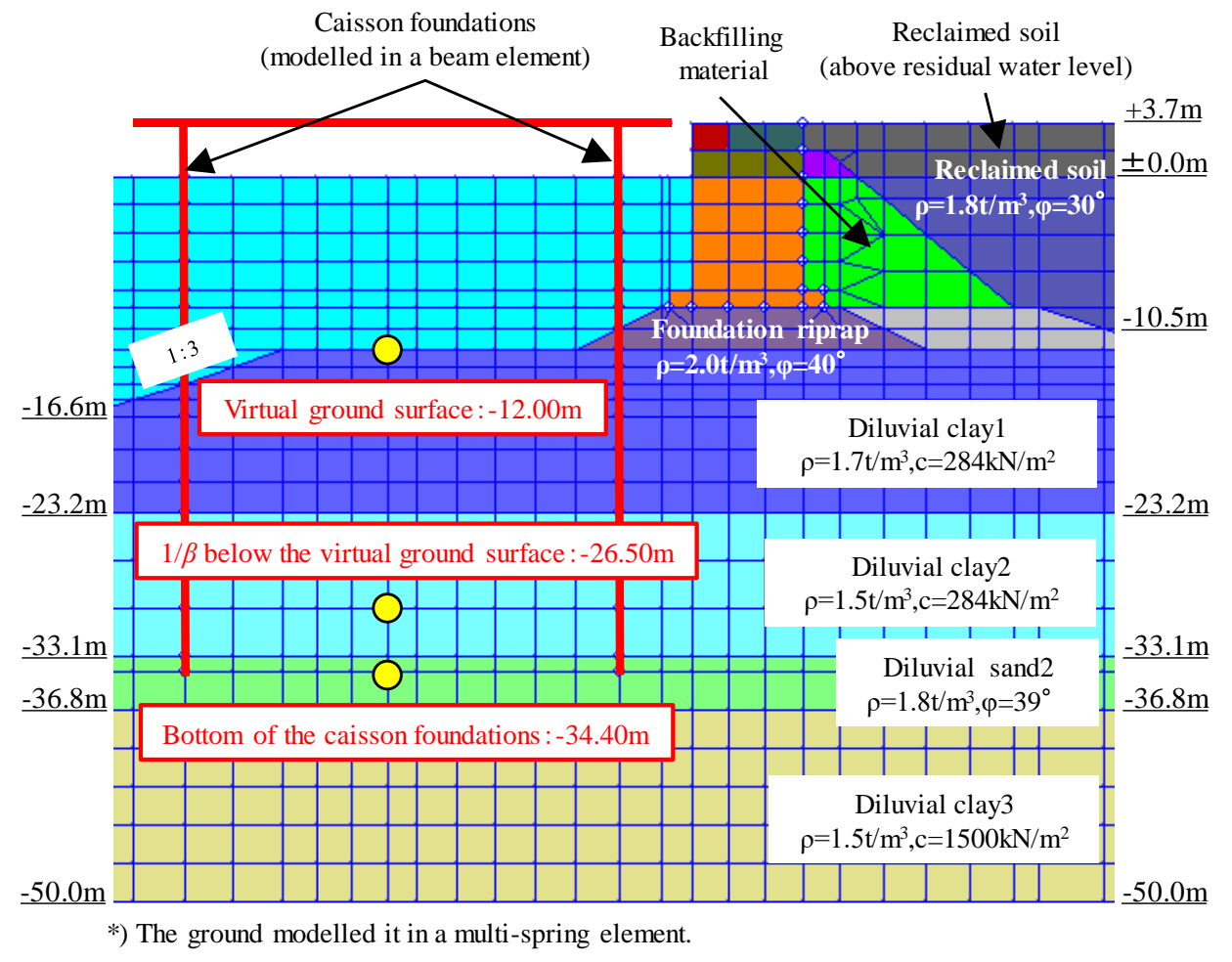

Figure 4. Numerical model (Case C)

Table 1. Wharf dimensions

\begin{tabular}{cccccc}
\hline $\begin{array}{c}\text { Analaysed } \\
\text { structures }\end{array}$ & $\begin{array}{c}\text { Caisson foundation } \\
\text { diameter }(\mathbf{m})\end{array}$ & $\begin{array}{c}\text { Caisson foundation pitch } \\
\text { in face-line direction }(\mathbf{m})\end{array}$ & $\begin{array}{c}\text { Virtual ground } \\
\text { surface }(\mathbf{m})\end{array}$ & $\begin{array}{c}\mathbf{1} / \boldsymbol{\beta} \text { below the virtual } \\
\text { ground surface }(\mathbf{m})\end{array}$ & $\begin{array}{c}\text { Bottom of the caisson } \\
\text { foundation }(\mathbf{m})\end{array}$ \\
\hline Case A & 6.5 & 20.0 & -11.95 & -29.70 & -36.00 \\
Case B & 3.7 & 14.0 & -7.84 & -15.46 & -16.50 \\
Case C & 5.5 & 20.0 & -12.00 & -26.50 & -34.40 \\
\hline
\end{tabular}




\subsection{Input earthquake ground motions}

The input earthquake ground motions were set by using the design earthquake ground motion to be applied to Tokyo Port (Maximum acceleration: $182 \mathrm{Gal}$, predominant frequency: $0.86 \mathrm{~Hz}$ ), which were made public on the homepage [16] of National Institute for Land and Infrastructure Management of the Ministry of Land, Infrastructure, Transport and Tourism.
Since these waveforms had two peaks in the vicinity of 0.86 $\mathrm{Hz}$ and $2.0 \mathrm{~Hz}$, the second peak was cut, and predominant frequencies varied to $0.2 \mathrm{~Hz}, 1.0 \mathrm{~Hz}$ and $2.0 \mathrm{~Hz}$ were used. Besides, amplitude adjustments were conducted to make all the maximum accelerations equal to $200 \mathrm{Gal}$. Acceleration time history and acceleration Fourier spectra of respective waveforms are shown in Figure 5.
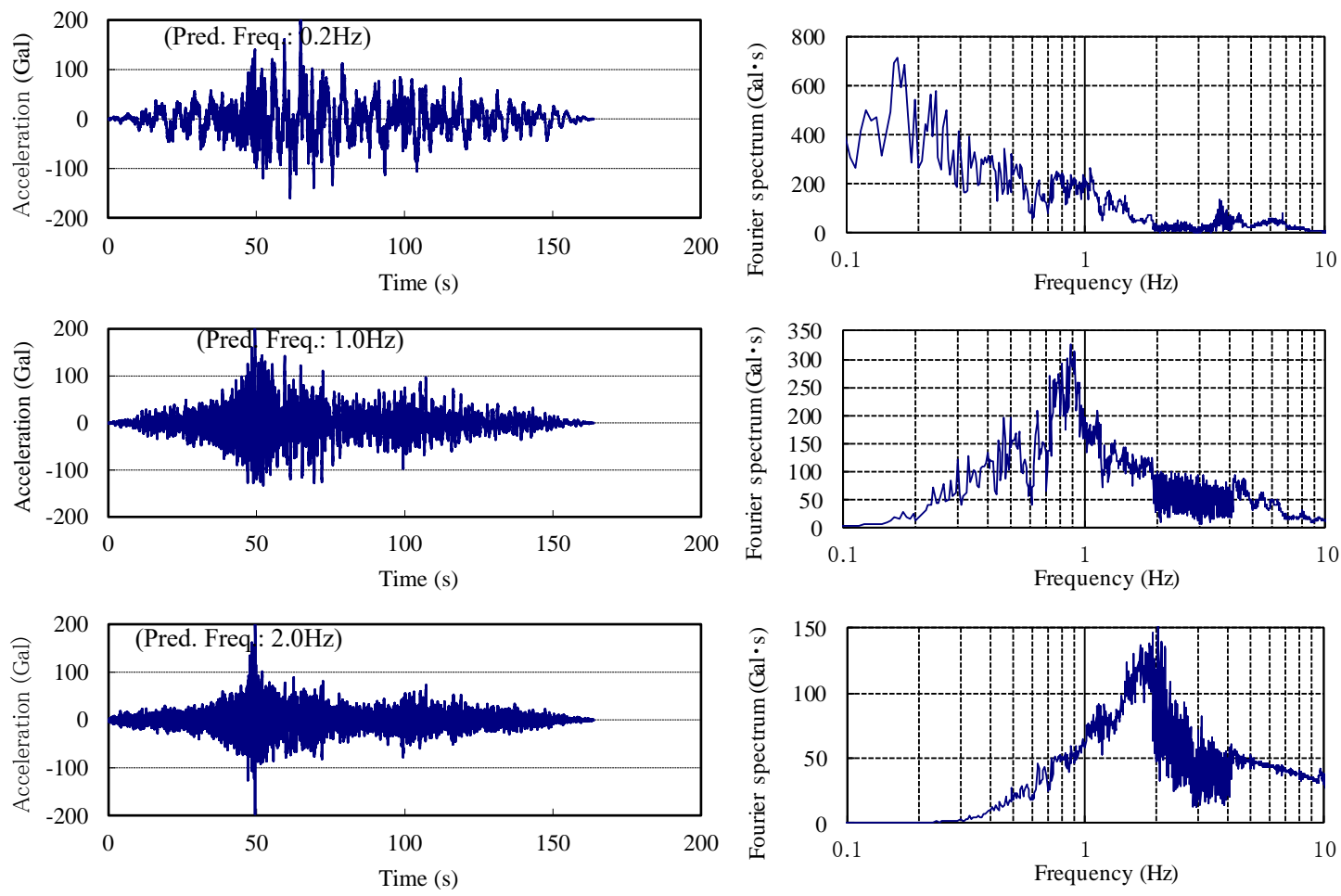

Figure 5. Acceleration Time History, Acceleration Fourier Spectrum

\section{RESULTS OF ANALYSIS}

\subsection{Natural period of wharf}

The natural period of a wharf has been set by processing and organizing the ratios of the acceleration Fourier spectra at the crown height of the wharf to the spectra obtained at (1) the virtual ground surface, (2) $1 / \beta$ below the virtual ground surface, and (3) the bottom of the caisson foundation, thereby reading out peak frequency and calculating its reciprocal.

Examples of acceleration Fourier spectra ratios are shown in Figure 6. Red circles are the positions of reading out the frequency peaks. Figure 7 shows the natural periods at the virtual ground surface and those at $1 / \beta$ below the virtual ground surface relative to the natural periods at the pile bottom. Both the natural periods at the pile bottom and those at $1 / \beta$ below the virtual ground surface agree with each other. Meanwhile, the natural periods at the virtual ground surface were found somewhat shorter than those at the pile bottom.

Since the ground shear modulus lowers due to the nonlinearity of the ground, which deepens the fixed point of the pile (making pile free length longer), the predominant periods of response acceleration at the virtual ground surface became longer than those at $1 / \beta$ below the virtual ground surface and at the pile bottom. Therefore, the peak spectral ratio at the virtual ground surface is considered to have become longer compared with the peak spectral ratios at the other two evaluated positions.

Another thing to point out is that the natural periods became longer when predominant frequencies of input seismic motions became lower. The reason is that seismic motions with short predominant frequencies caused smaller rigidity and longer periods of the ground.

\subsection{Earthquake response of wharf}

Figure 8 shows acceleration response spectra obtained through the two-dimensional analysis in the central part of the wharf. Here, red circles in these figures represent the maximum value of response acceleration of superstructure obtained through the two-dimensional analysis. Four values of damping constants, i.e. $5 \%, 10 \%, 15 \%$ and $20 \%$ were utilized in calculating the acceleration response spectra. This is because of having taken into account the possible necessity to set larger damping constants than those employed for ordinary structures since seismic behaviour in the central part of the wharf can be affected significantly by slopes and caisson foundations. The spots focused in red circles in the figures have shown a tendency that according as the evaluation positions of the acceleration response spectra become shallower in the order of pile bottom, $1 / \beta$ below the virtual ground surface and virtual ground surface, the peak spectra tend to move toward the longer frequency side.

Likewise, the lower the predominant frequency of input 
earthquake ground motions, the stronger this tendency. This seems to be due to the fact that if the predominant frequency of input earthquake ground motions is lower, frequency components that contribute to the ground displacement increase in number, and larger ground displacements have reduced the shear modulus of the ground. Focusing on the relation between the maximum response acceleration obtained by the two-dimensional analysis and that by the acceleration response spectra corresponding to the respective damping constants, the maximum response acceleration by the twodimensional analysis is smaller than that by the acceleration response spectra with the damping constant of $20 \%$ for Case B. On the contrary, acceleration of Case $\mathrm{C}$ turned out to be larger than the acceleration response spectra with the damping constant of $5 \%$. Case A resulted in acceleration response spectra with damping constant fluctuating between $5 \%$ and $20 \%$. Figure 9 shows the errors plotted versus the damping constant of acceleration response spectra. Here, $\alpha 2$ is the maximum acceleration obtained from the two-dimensional analysis and $\alpha 1$ is that by the acceleration response spectra and those plotted in colour indicate average values. As a result of our examination, in Case $\mathrm{A}$ and Case $\mathrm{C}$, the combination of "damping constant of $5 \%$ and at the bottom end of the pile" has allowed the most accurate evaluation of the maximum acceleration at the crown height of the wharf. On the other hand, in Case B, the combination of "damping constant of $20 \%$ and at the bottom end of the pile" has facilitated the most accurate evaluation of the maximum crown height acceleration. Furthermore, Case A and Case B showed a tendency that the shallower the position of evaluating response spectra at whichever damping constant, the larger the $\alpha 1 / \alpha 2$ ratio which represents a calculation error. Case $\mathrm{C}$, however, has not shown that tendency.
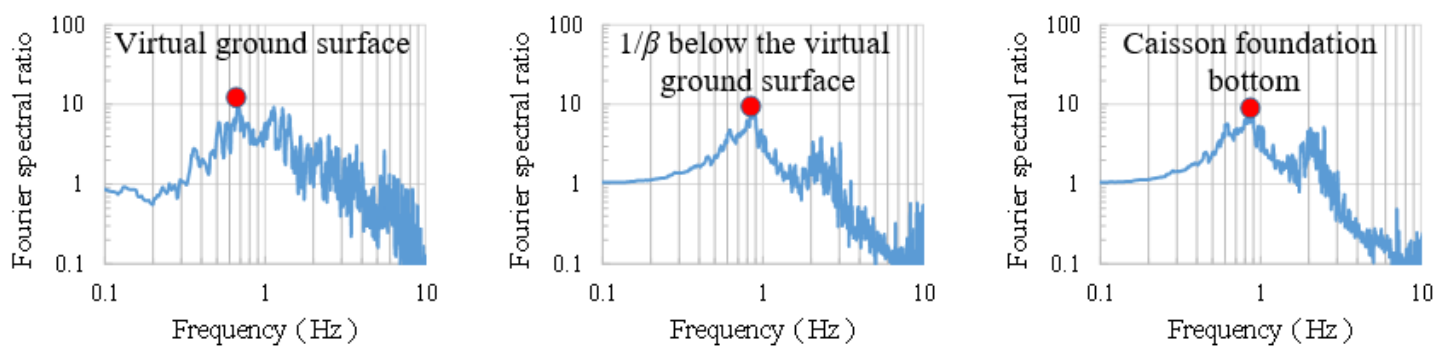

Figure 6. Fourier spectral ratio (Case A)
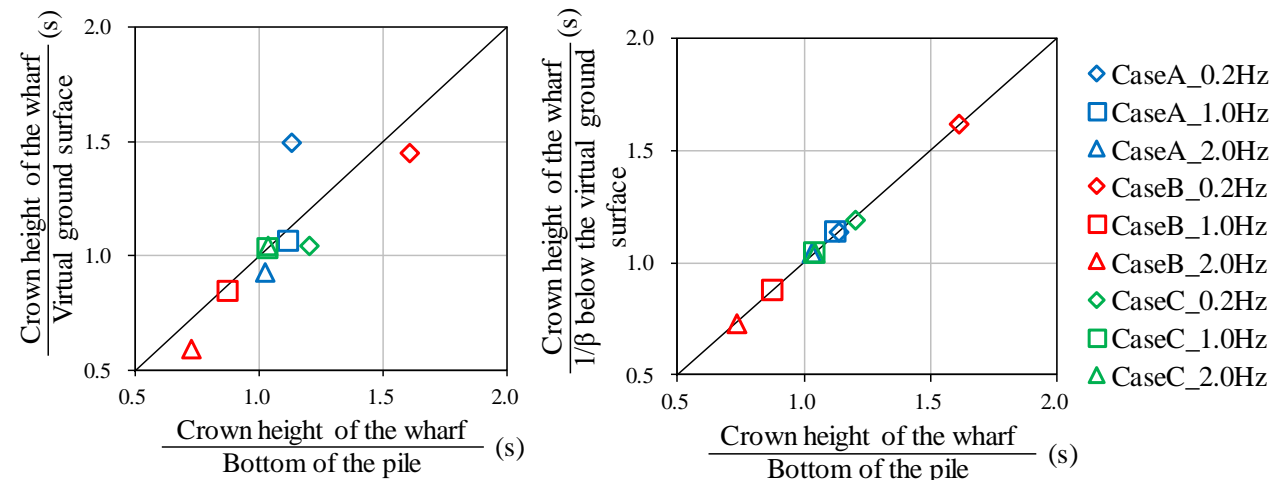

Figure 7. Comparison of natural periods of wharves
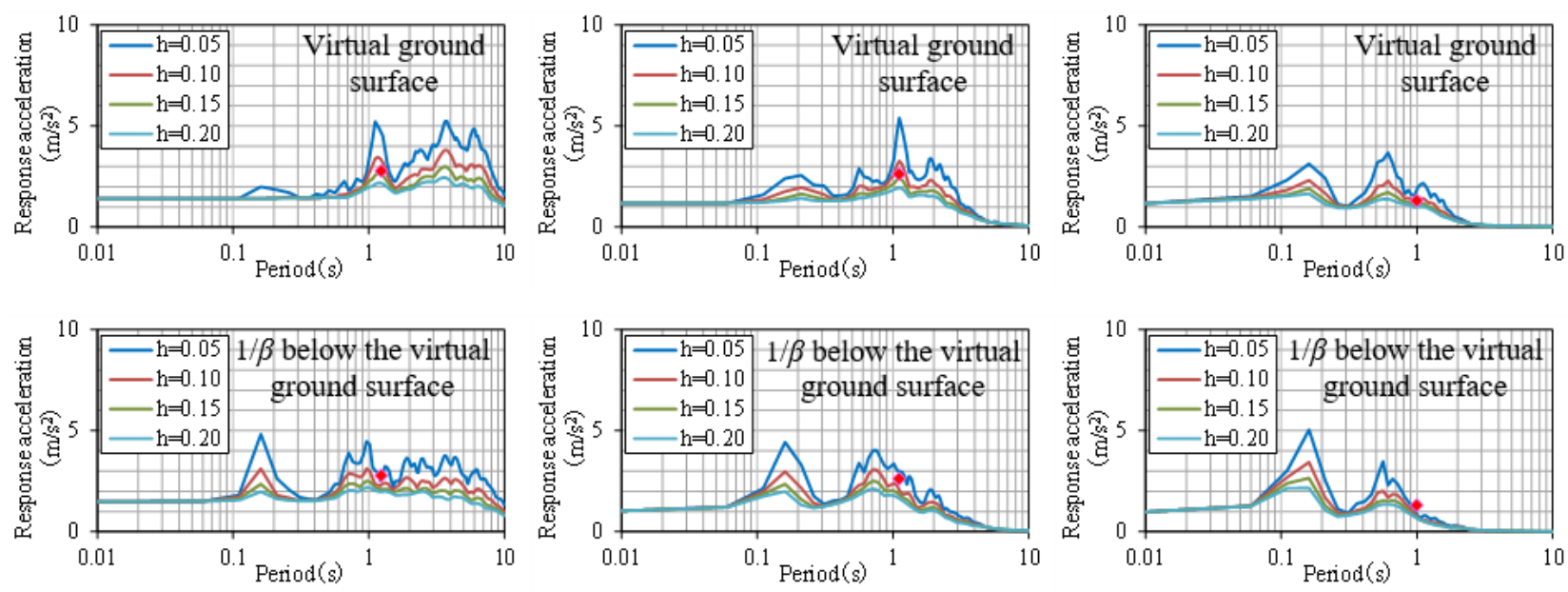

Figure 8. Acceleration response spectra 


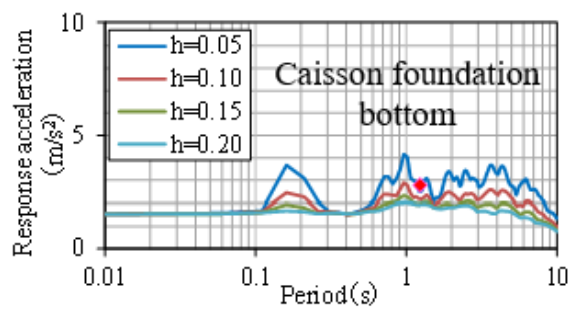

(i) Case A_Pred.Freq.:0.2Hz
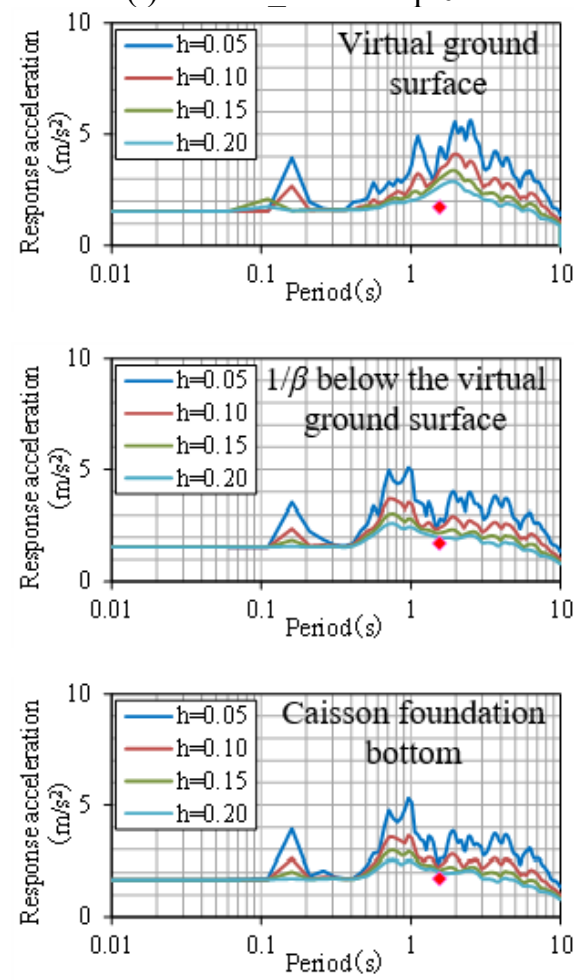

(iv) Case B_Pred.Freq.:0.2Hz
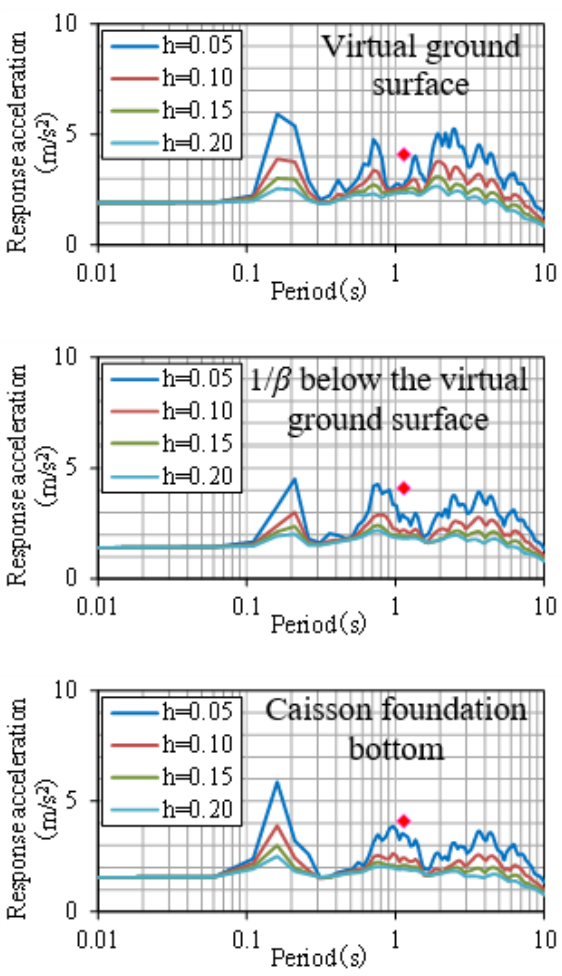

(vii) Case C_Pred.Freq.:0.2Hz

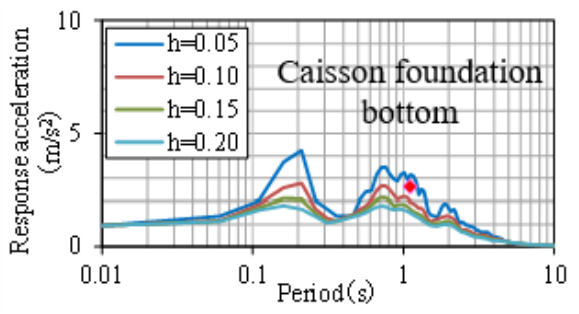

(ii) Case A Pred.Freq.:1.0Hz
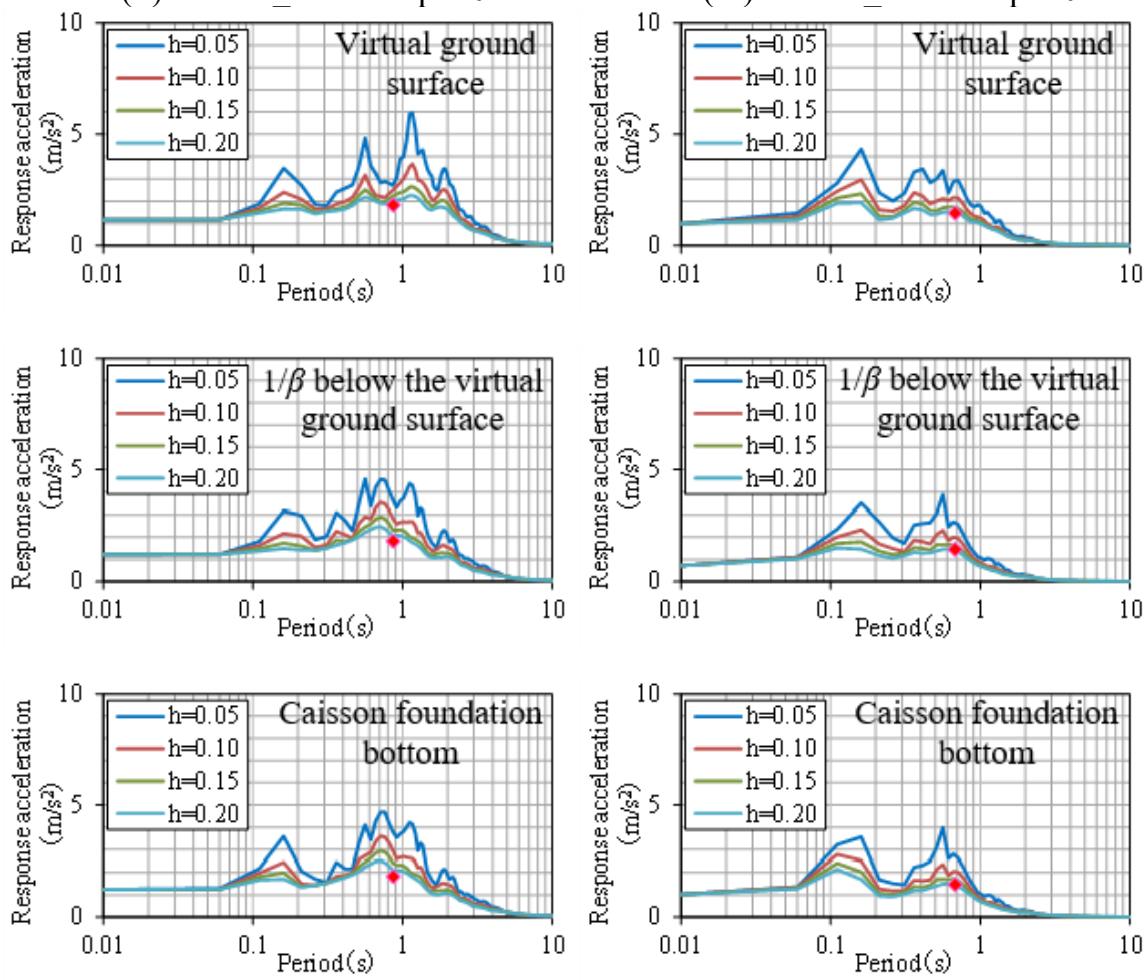

(v) Case B_Pred.Freq.:1.0Hz
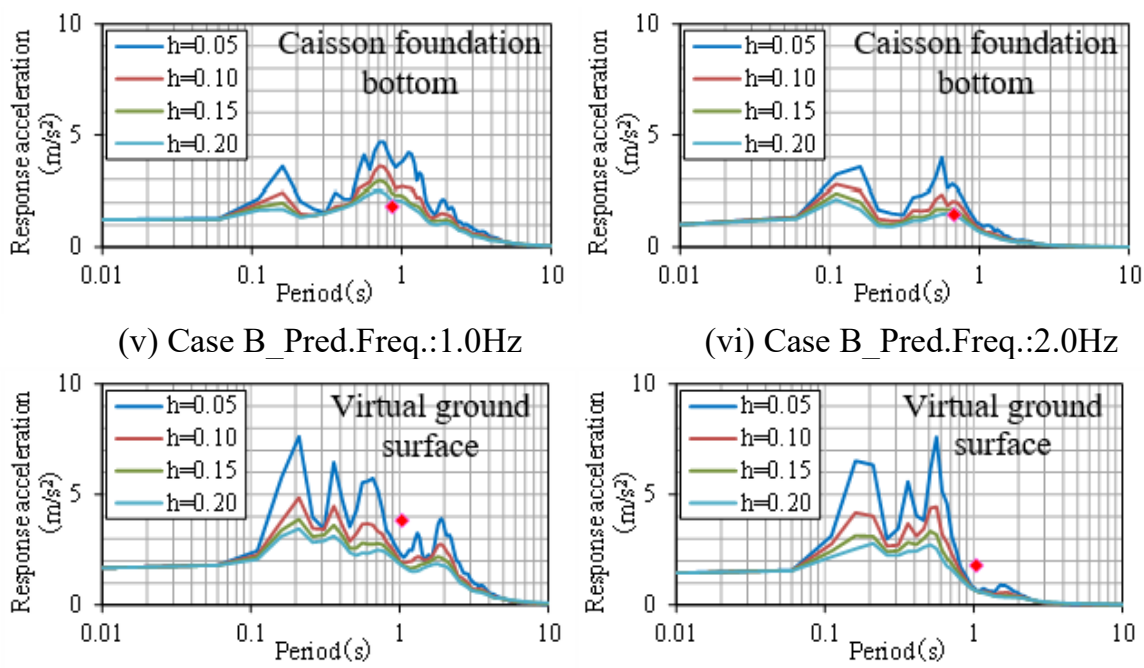

(vi) Case B_Pred.Freq.:2.0Hz
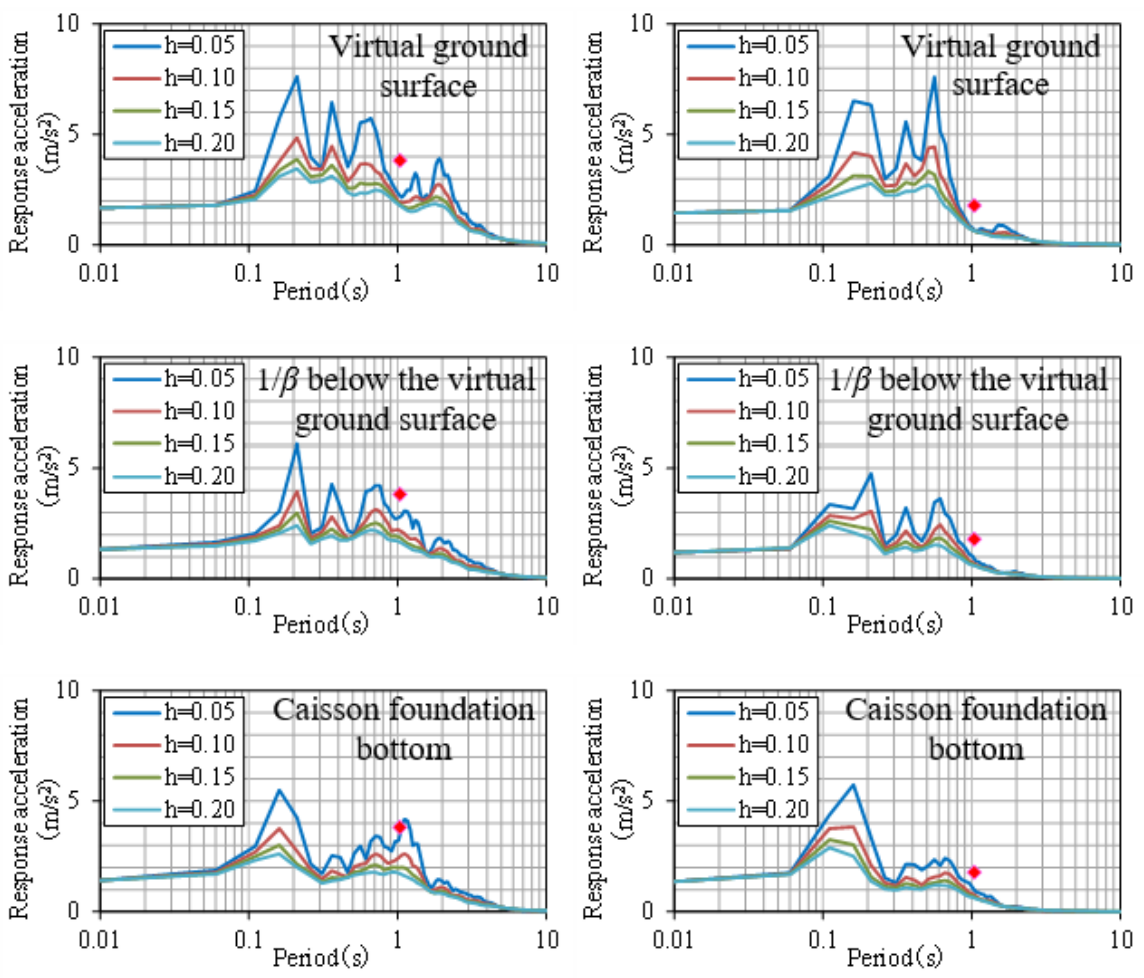

(ix) Case C_Pred.Freq.:1.0Hz

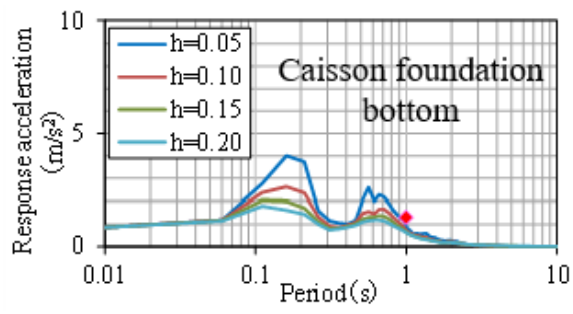

(iii) Case A_Pred.Freq.:2.0Hz

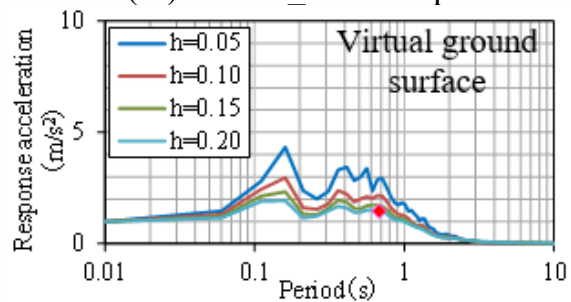



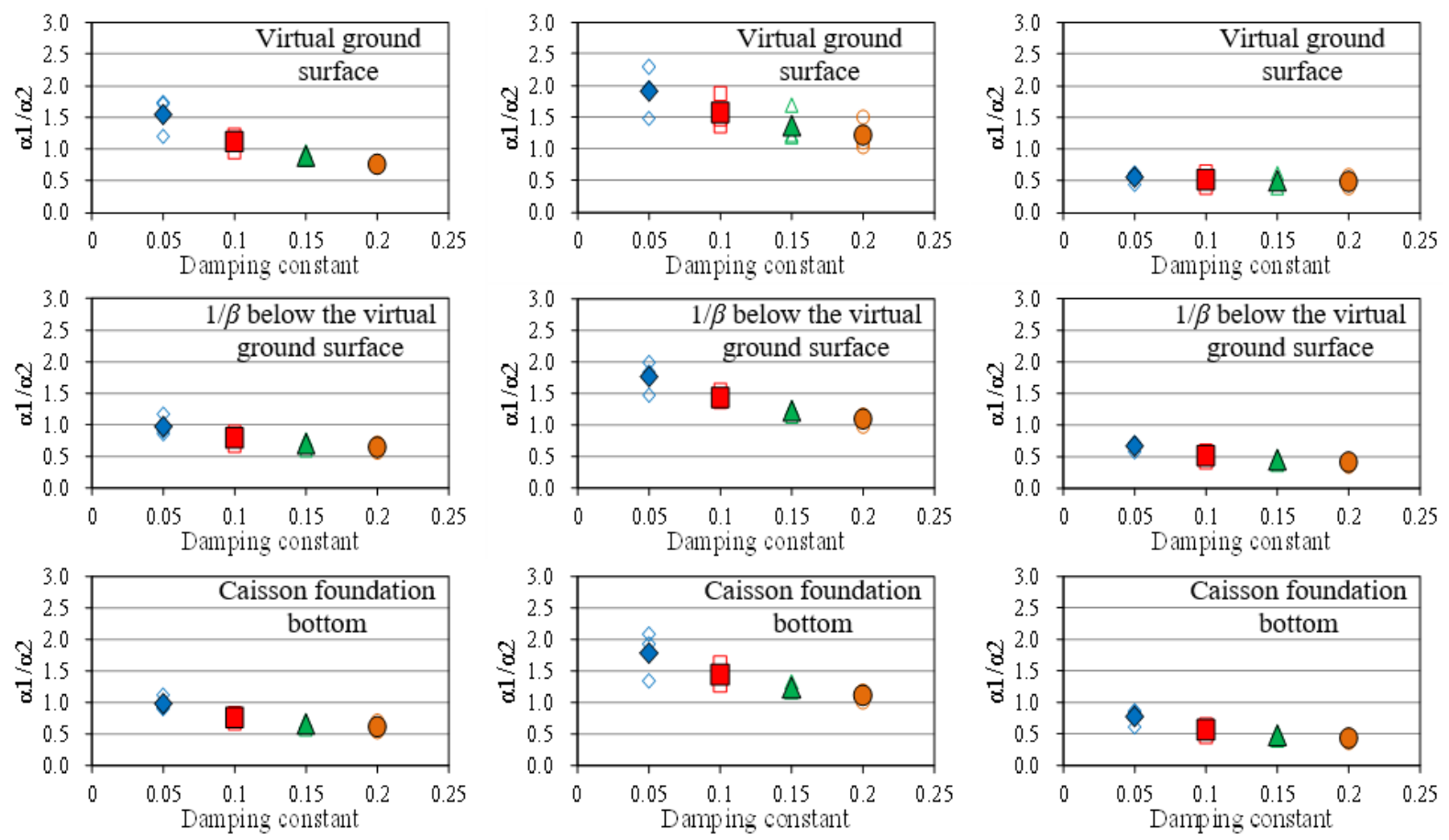

(i) Case $\mathrm{A}$

(ii) Case B

(iii) Case $\mathrm{C}$

Figure 9. Relation between response acceleration calculation errors and damping (two-dimensional analysis)

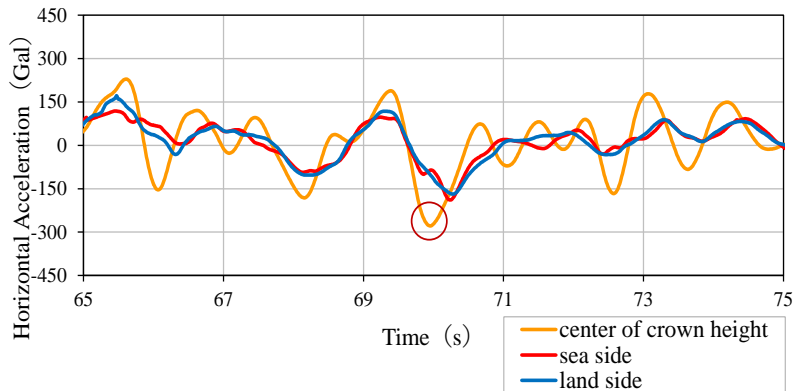

(i) Case A: Virtual ground surface

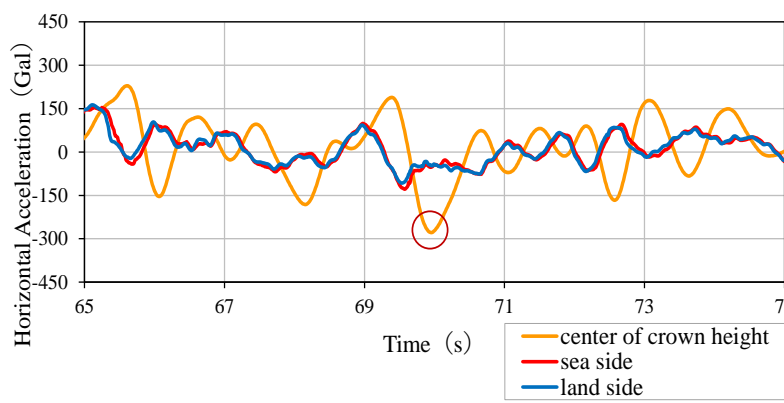

(iii) Case A: Caisson foundation bottom

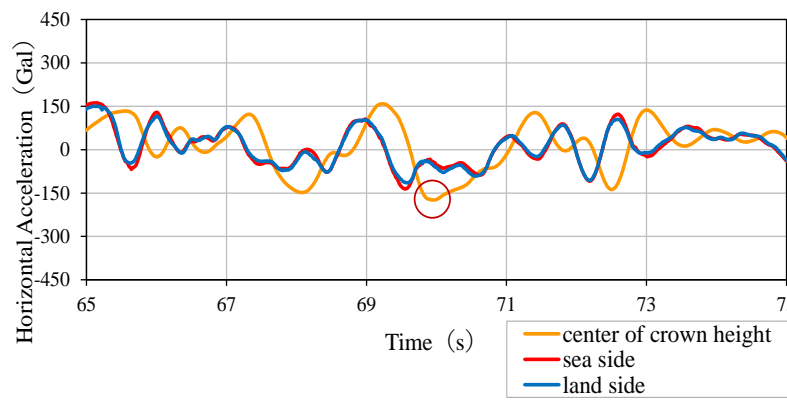

(v) Case B: $1 / \beta$ below the virtual ground surface

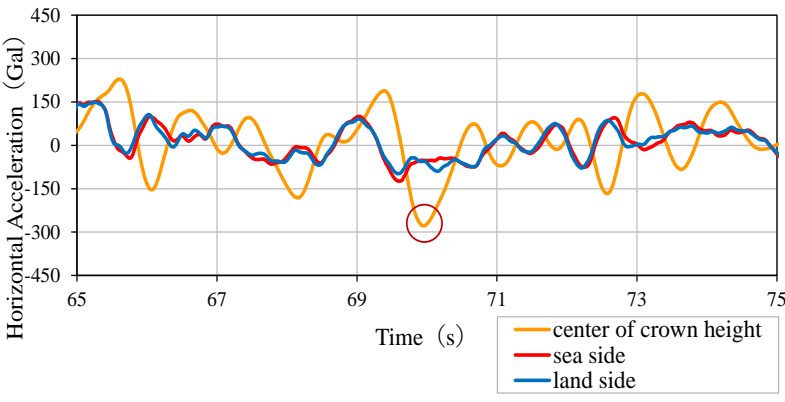

(ii) Case A: $1 / \beta$ below the virtual ground surface

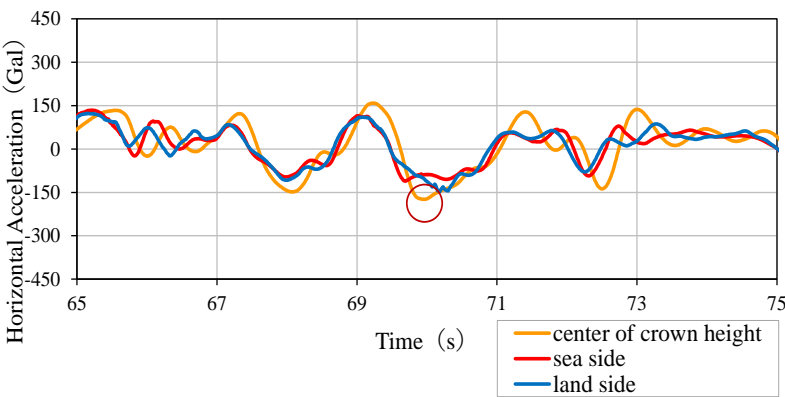

(iv) Case B: Virtual ground surface

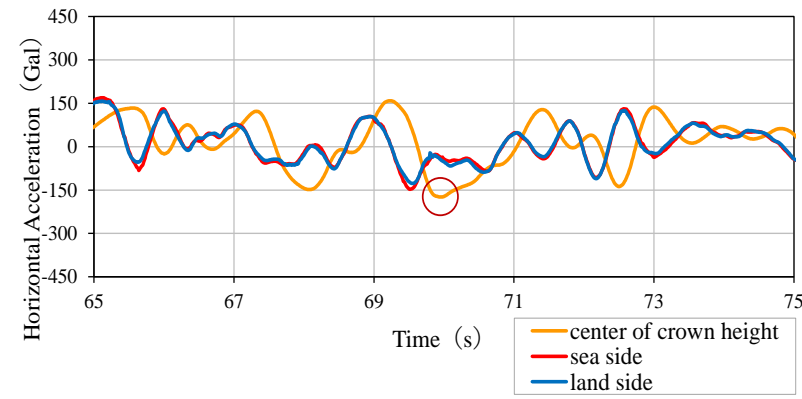

(vi) Case B: Caisson foundation bottom 


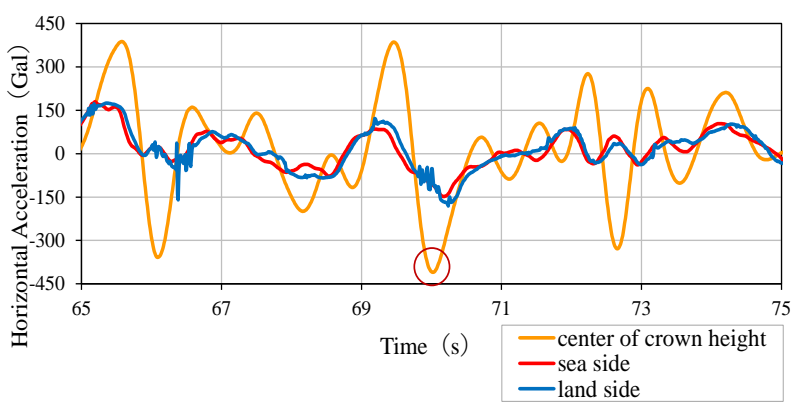

(vii) Case C: Virtual ground surface

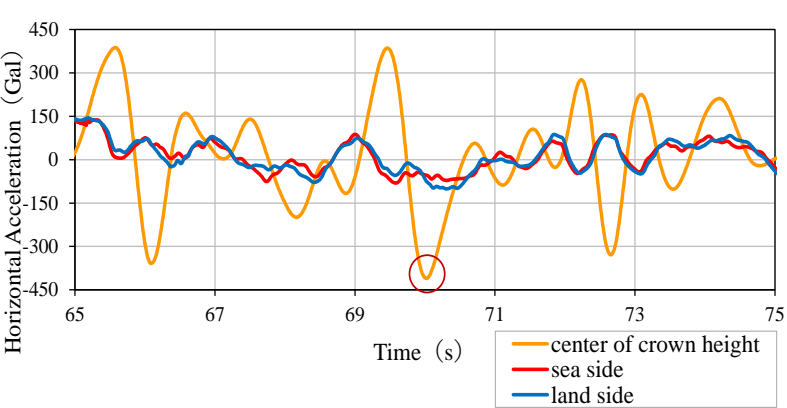

(viii) Case $\mathrm{C}: 1 / \beta$ below the virtual ground surface

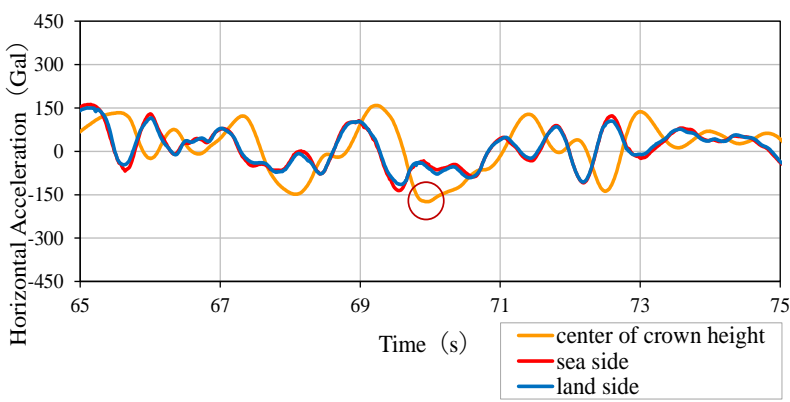

(v) Case B: $1 / \beta$ below the virtual ground surface

Figure 10. Time history of horizontal acceleration at the central part of the crown, at the sea side piles and at the land side piles

Focusing on the time around which response acceleration at the crown height of the wharf becomes the largest, Figure 10 shows examples of the time history of horizontal acceleration at the central part of the crown, at the sea side piles and at the land side piles (Predominant Frequency: $0.2 \mathrm{~Hz}$ ). Those marked in red circles signify the spots where maximum acceleration response is being generated at the central part of the crown of the wharf. As a result, the shallower the depth, the greater the phase difference in ground displacement between the sea side and the land side, making vibrations strongly susceptible to the effects of the ground. This seems to be because, in case of focusing on the position of the virtual ground surface with a shallow depth, the depth from the real ground surface to the virtual one at the sea side piles becomes shallower than the depth from the real ground surface to the virtual ground surface at the land side piles being affected by the slope, and hence a difference in confining pressure was generated between the sea and land sides. Consequently, the greater the depth, the higher the confining pressure on both the sea and the land sides, making effects due to the difference between the sea and the land sides smaller, thereby reducing the phase difference in ground displacement. Namely, the shallower the evaluating position of response spectra, the greater the phase difference in ground displacement between the sea and the land sides being affected by the slope, which has become a response diverged from the single degree of freedom system, and the response acceleration has presumably resulted in overestimation if not setting larger damping constants. Consequently, in Case A and Case B, shallower evaluating positions of response spectra seem to have enlarged the calculation error $\alpha 1 / \alpha 2$. On the other hand, since Case C does not suppose a slope but a level right under the wharf, having few effects of the difference between the sea and the land sides, and hence no tendency similar to Case A and Case $\mathrm{B}$ was presumably observed. Focusing next on pile pitch, slope gradient and pile length of respective examination structures, it has turned out that pile pitch of Case A is $38 \mathrm{~m}$ and that of Case C $30 \mathrm{~m}$ both in right angles to the face line, whereas pile pitch of Case B is as small as $14 \mathrm{~m}$. As regards the slope, Case A has a gradient of $1: 3$, and Case $C$ is flat, whereas Case $B$ has a steep gradient of 1:2. Furthermore, Case A and Case $C$ have uniform pile lengths on both sea and land sides, whereas Case B supposes the sea side length longer than the land side one. For this reason, the effect of the difference in the response between the sea and land sides in Case B becomes larger than in Case A and Case C, which presumably made it necessary to set the optimum damping constant at $20 \%$ which is larger than for normal structures.

The construction time of Case B is so old that if the concepts of current port facility standards are applied, resulting structural dimensions will highly likely have deviations from those shown in Figure 2. On the basis of the foregoing results, the vibration centre of a pneumatic caisson foundation is at the bottom of caisson foundation, and hence the damping constant of a $5 \%$ level is considered to be enough as the damping of a structure.

\section{CONCLUSION}

Targeting an open-type wharf with a pneumatic caisson foundation of a highly rigid structure, and in order to acquire fundamental information for establishing an earthquake resistant design method, we have predicted the seismic behaviour of an open-type wharf on a caisson foundation using a two-dimensional non-linear finite element analysis.

In order to have a grasp of the seismic behaviour of an opentype wharf with a pneumatic caisson foundation, we conducted the two-dimensional non-linear finite element analysis by varying the frequency characteristics of the input earthquake ground motions; likewise we varied tentatively the positions to evaluate acceleration response spectra at the three levels of (1) virtual ground surface, (2) $1 / \beta$ below the virtual ground surface and (3) the bottom end of the pile; and also varied the damping constants for use to evaluate acceleration response spectra to the four sorts of $5 \%, 10 \%, 15 \%$ and $20 \%$. 
We thereby examined several combinations of the positions for evaluating acceleration response spectra and the damping constants with a view to verifying which combination will give an optimum reproducibility of the maximum response acceleration on the crown of the wharf. Using the result of the examination, we analysed the differences between the wharf with a pneumatic caisson foundation and the wharf on a steel pipe pile foundation which have structural rigidity different from each other. The achievements of this study are summarized as follows:

(1) Focusing on the time around which the maximum response acceleration on the crown of the wharf is generated, we made arrangement of horizontal acceleration time histories evaluated at the central part of the crown, at the sea-side pile position, and at the land-side pile position of the wharf. It has turned out that the smaller the depth, the larger the phase difference between the sea-side and the land-side, with vibrations considerably vulnerable to the properties of the ground. This is presumably attributable to the disparity in the confining pressure which has been generated by the existence of the slope.

(2) On the basis of the natural period of the wharf calculated from the acceleration Fourier spectral ratio, we have studied combinations of the positions for evaluating acceleration response spectra and the damping constants that would enable adequate evaluation of the maximum response acceleration at the crown of the wharf. The following are the results: For both Case A and Case C, the optimum combination is "at the bottom end of the pile and the damping constant of 5\%," and for Case B, "at the bottom end of the pile and the damping constant of $20 \%$." The reason of Case B resulting in larger damping is that the steep slope and the difference in the pile length between the sea-side and the land-side have caused a larger influence of the phase difference between the sea-side and the land-side.

\section{ACKNOWLEDGEMENTS}

We express our deep gratitude for the favour of Dr. Masahiko Oishi of Oriental Shiraishi Co., Ltd. of having provided us with relevant data and valuable opinions during this research.

\section{REFERENCES}

[1] Ports and Harbours Bureau, Ministry of Land, Infrastructure, Transport and Tourism (MLIT), National Institute for Land and Infrastructure Management, MLIT and Port and Airport Research Institute. (2009). Technical Standards and Commentaries for Port and Harbour Facilities in Japan of 2009. The Overseas Coastal Area Development Institute of Japan.

[2] Shibata, D., Nagao, T. (2018). Earthquake response an of open-type wharf with a pneumatic caisson foundation. WIT Transactions on The Built Environment, 180: 209225. https://doi.org/10.2495/SUSI180191
[3] Sano, T. (1916). Earthquake resistant structure theory of house. Earthquake Prevention Investigation Report. (in Japanese).

[4] Iai, S. (1998). Seismic analysis and performance of retaining structures. Geotechnical Earthquake Engineering and Soil Dynamics III, Geotechnical Special Publication No.75, ASCE, pp. 1020-1044.

[5] Takahashi, A., Takemura, J. (2005). Liquefactioninduced large displacement of pile-supported wharf. Soil Dynamics and Earthquake Engineering, 25(11): 811-825. https://doi.org/10.1016/j.soildyn.2005.04.010

[6] Hamid, H.T., Khosrow, B., Rouhollah, A., Nason, J.M. (2014). Fragility estimation and sensitivity analysis of an idealized pile-supported wharf with batter piles. Soil Dynamics and Earthquake Engineering, 61-62: 92-106. https://doi.org/10.1016/j.soildyn.2014.01.024

[7] Lei, S., Jinchi, L., Ahmed, E., Arul, K.A. (2017). Seismic performance of a pile-supported wharf: Threedimensional finite element simulation. Soil Dynamics and Earthquake Engineering, 95: 167-179. https://doi.org/10.1016/j.soildyn.2017.01.009

[8] Nagao, T., Oda, T. (2017). Evaluation of the damage level of open-type wharf by earthquake focusing on the natural frequency. Proc. of ICOSSAR2017.

[9] Oishi, M., Nagao, T., Motegi, K., Ouchi, M., Sato, Y., Kiyomiya, O. (2012). A study on the seismic behaviour and verification method for earthquake performance of an open-type wharf with pneumatic caissons. Journal of JSCE A1 (Structural Engineering and Earthquake Engineering) of Japan Society of Civil Engineers, 68(4). (in Japanese).

[10] Oishi, M., Nagao, T., Ouchi, M., Sato, Y., Kiyomiya, O. (2013). A study on the verification method for earthquake performance of an open-type wharf with pneumatic caissons. Journal of JSCE B3 (Ocean Development) of Japan Society of Civil Engineers, 69(2). (in Japanese).

[11] Iai, S., Matsunaga, Y., Kameoka, T. (1992). Strain space plasticity model for cyclic mobility. Soils and Foundations, 32(2): 1-15.

[12] Towhata, I., Ishihara, K. (1985). Modelling soil behaviour under principal stress axes rotation. Proc. of 5th International Conf. on Num. Methods in Geomechanics, Nagoya, 1: 523-530.

[13] Hardin, B.O., Drnevich, V.P. (1972). Shear modulus and damping in soils: design equation and curves. Journal of the Soil Mechanics and Foudations Division, 98(7): 667692.

[14] Suetomi, I., Yoshida, N. (1998). Nonlinear behaviour of surface deposit during the 1995 Hyogoken-Nambu earthquake. Soils and Foundations, 38: 11-22. https://doi.org/10.3208/sandf.38.Special_11

[15] Morita, T., Iai, S., LIU, H., Ichii, K., Sato, Y. (1997). Simplified setting method of various required parameters in prediction program FLIP. Technical note of the Port and Harbour Research Institute. Ministry of Transport. Japan, No. 869. (in Japanese).

[16] http://www.ysk.nilim.go.jp/kakubu/kouwan/sisetu/sisetu .html, accessed on 16 December 2019. 